\title{
Ovicidal and larvicidal activity of Cassia alata leaf acetone extract and fractions on
} Haemonchus contortus: in vitro studies

\author{
I.O. Ademola ${ }^{1,2}$, A.F. Vatta ${ }^{3,4}$, J.N. Eloff ${ }^{1}$
}

${ }^{1}$ Phytomedicine Programme, Department of Paraclinical Sciences, Faculty of Veterinary Science, University of Pretoria, Onderstepoort 0110, South Africa.

${ }^{2}$ Department of Veterinary Microbiology and Parasitology, Faculty of veterinary Medicine, University of Ibadan, Ibadan, Nigeria

${ }^{3}$ Onderstepoort Veterinary Institute Private Bag X05 Onderstepoort 0110 South Africa

${ }^{4}$ Ross University School of Veterinary Medicine P.O. Box 334 Basseterre St Kitts and Nevis

West Indies

\begin{abstract}
s
The failure of modern broad spectrum anthelmintics to control nematode parasites of sheep and goats is a reality, of rapidly increasing dimension, on many farms in the tropical / subtropical regions of the world. This requires research alternatives and plant secondary metabolites is one of those solutions. Cassia alata was extracted with acetone (70\%) and fractions were obtained by solvent:solvent group separation procedure. The acetone extract and the fractions was tested by egg hatch inhibition (EHA) and larval development and viability assay (LDVA) in vitro to assess relative bioactivity Haemonchus contortus eggs and larvae. The extracts inhibited egg hatchability and killed infective larvae of $H$. contortus in a concentration-dependent manner. Best-fit $\mathrm{LC}_{50}$ values were $0.562,0.243,0.490,0.314$ and $0.119 \mathrm{mg} / \mathrm{ml}$ for acetone extract, chlororform, hexane, butanol and 35\% water in methanol fractions respectively when tested against nematode eggs. While the best-fit $\mathrm{LC}_{50}$ values were $0.191,0.505,1.444,0.306$ and 0.040 $\mathrm{mg} / \mathrm{ml}$ for acetone extract, chloroform, hexane, butanol and 35\% water in methanol fractions respectively when tested against nematode larvae. The $35 \%$ water in methanol fraction was the
\end{abstract}


most active against the larvae and eggs of $H$. contortus demonstrating the lowest $\mathrm{LC}_{50}$ values. Albendazole produced $\mathrm{LC}_{50}$ at low concentrations $(0.164$ and $0.144 \mu \mathrm{g} / \mathrm{mL})$ on egg hatch inhibition and larval viability tests, indicating susceptibility of the strain of $H$. contortus used in the current study. Extracts of $C$. alata could find application in the control of helminths in livestock.

Keywords: Cassia alata, egg hatch assay, Haemonchus contortus, larval development assay, solvent:solvent fractions.

\section{Introduction}

Helminth infections of food animals cause significant economic losses. The effect of the infection is determined by a combination of factors of which the varying susceptibility of the host species, the pathogenecity of the parasite species, the host/parasite interaction, and the infective dose are the most important. The economic losses are closely associated with the extent to which the pathogenic effect of helminth infections influences the production of the individual host. This may vary considerably from clinical disease including mortality to chronic production losses which may appear as reduced growth rate, weight loss and/or reduced fecundity or it may go unnoticed.

C. alata leaf is credited for the treatment of haemorrhoids, constipation, inguinal hernia, intestinal parasitosis, blennorrhagia, syphilis and diabetes Adjanahoun et al (1991). This plant contains many diverse constituents such as alkaloids, lectins, saponins, cyanogenic, glycosides, isofilavones, and phytoestrogens Leeuwenberg (1987). Two new glycosides were isolated from the seeds of $C$. alata: chrysoeriol-7-0-(2"-0-beta-D-mannopyranosyl)-beta-D-allopyranos ide and 
rhamnetin-3-0-(2"-0-beta-D-mannopyranosyl)-beta-D-allopyranoside Gupta, (1991). Many alkaloids are pharmacologically active substances, which possess various physiological activities in humans and animals. The use of alkaloid-containing plants as dyes, spices, drugs or poisons can be traced back almost to the beginning of civilization.

In this study we report the ovicidal and larvicidal activity of acetone extract of C. alata leaf, and the relative activity of the solvent:solvent fractions against the eggs and larvae of gastrointestinal nematodes of sheep.

\section{Materials and Methods}

\subsection{Plant extracts preparation}

The leaf of the plant $C$. alata was collected in Zaria, Nigeria. Voucher specimens (No: 2421) were identified and deposited by the herbarium section of the biological sciences department, Ahmadu Bello University, Zaria. The plant material (120g) was air dried and ground to powder using a Macsalab Model 200 LAB grinder. The extract was prepared by maceration with shaking (Labotec Model 20.2 shaker) for $24 \mathrm{~h}$ in $70 \%$ acetone with a 10:1 solvent to dry weight ratio (Eloff, 1998) and the extract was filtered through Whatman No 1 filter paper using a Buchner funnel, and the acetone removed by air drying.

Solvent:solvent group separation procedure used by the USA National Cancer Institute as described by Suffness and Douros (1979) was adopted to fractionate the acetone extract with a slight variation. The acetone extract was taken to dryness in a rotary evaporator under reduced pressure and this extract was dissolved in a 1:1 mixture of chloroform and water. The water fraction was extracted with an equal volume of butanol in a separating funnel to yield the water 
and butanol fractions. The chloroform fraction was taken to dryness in a rotary evaporator under reduced pressure and extracted with a 1:1 mixture of hexane and 10\% water in methanol. The hexane fraction was recovered with a separating funnel. The $20 \%$ water in methanol extract was diluted to $35 \%$ methanol in water and extracted with chloroform to yield the chloroform fraction and the $35 \%$ water in methanol fractions. In all cases equal volumes of the solvents were used and the extraction was repeated with a small volume approximately three more times or until the entire colour was extracted.

\subsection{H. contortus egg recovery}

H. contortus eggs were recovered according to Hubert and Kerboeuf (1992). A sample of faeces (10 to $15 \mathrm{~g}$ ) from sheep experimentally infected with mono-specific larval suspensions of fresh $H$. Contortus (References: $H$. contortus ex F. van Schalkwyk. Strain no: BZ/OP/2/P2/HcOP) obtained from Biozetica Agri-source (Pty) Ltd. Ondersteeport, Pretoria. The faecal sample was suspended in water and cleared of organic debris by filtration through $1 \mathrm{~mm}$ and $150 \mu \mathrm{m}$ sieves. Eggs were collected on a $25 \mu \mathrm{m}$ sieve and further cleared of organic debris by centrifugation in magnesium sulphate (density $1: 10$ ) for five minutes at $1000 \mathrm{~g}$. The supernatant was filtered through $100 \mu \mathrm{m}$ and $63 \mu \mathrm{m}$ sieves and the eggs were washed in water and collected on a $25 \mu \mathrm{m}$ sieve. The concentration of eggs was estimated in $200 \mu \mathrm{l}$ samples and adjusted to 500 eggs $/ \mathrm{ml}$. $5 \mu \mathrm{g} / \mathrm{ml}$ amphotericine B solution (Sigma) was added to the egg suspension to avoid fungal development. 


\subsection{Egg hatch test}

The in vitro egg hatching test was based on the method described by Coles et al. (1992). A suspension of $0.2 \mathrm{ml}$ was distributed in a 48-flat-bottomed microtitre plate containing approximately 100 fresh eggs/well and mixed with the same volume of plant extract at concentrations of $10 \mathrm{mg} / \mathrm{ml}$ in 8 serial dilutions. Albendazole ( $99.8 \%$ pure standard reference) was used as a positive control. Albendazole was dissolved in dimethyl sulfoxide (0.3\% DMSO) and diluted at the concentrations of between $1 \mu \mathrm{g} / \mathrm{ml}$ and $0.0075 \mu \mathrm{g} / \mathrm{ml}$. The control plates contained the diluents water and acetone or $0.3 \%$ DMSO, depending on the extract, and the egg solution. The eggs were incubated in this mixture for $48 \mathrm{~h}$ at $27^{\circ} \mathrm{C}$ and $70 \%$ relative humidity. After this time a drop Lugol iodine solution (Reidel de Hae) was added to stop the eggs from hatching. All the eggs and first-stage larvae $\left(L_{1}\right)$ in each plate were counted. There were three replicates for each concentration and control.

\subsection{Larval viability test}

The procedures used were a modification of the technique described by Hubert and Kerbouef (1992). $150 \mu \mathrm{l}$ aliquots of a suspension with about 100 eggs/well, and $20 \mu \mathrm{l}$ of filtrate obtained by faecal washing during egg recovering were distributed to wells of a 48-well flat-bottomed microtiter plate. This suspension was supplemented with $30 \mu \mathrm{l}$ of the nutritive medium described by Hubert and Kerboeuf (1984) and comprised of Earle's balanced salt solution (Sigma) plus yeast extract (Sigma) in saline solution ( $1 \mathrm{~g}$ of yeast extract/90 $\mathrm{ml}$ of saline solution) at a ratio of 1:9 v/v. The plates were incubated at $27^{\circ} \mathrm{C}$ and $70 \%$ relative humidity. After $48 \mathrm{~h}, 200 \mu \mathrm{l}$ of the extract or diluent (control) were added. The third stage larvae were obtained six days later. At this time the parasites were counted by separating the larvae into two classes, third-stage larvae 
$\left(L_{3}\right)$ and other developmental stages larvae $\left(L_{1}\right.$ and $\left.L_{2}\right)$. There were three replicates for each concentration and control.

\subsection{Statistical analysis}

The $\mathrm{LC}_{50}$ was determined by computing the concentration of extract that gave a response halfway between the minimum and maximum responses in a concentration-response sigmoid curve. The relation below gives the egg hatch and larval viability parameter respectively:

Number of larvae/ Total number of larvae and eggs in wells with plant extract

Number of larvae/ Total number of larvae and eggs in control well (water)

Number of living L3 / Total number of nematode in wells with plant extract

Number of living L3/ Total number of nematode in control well (water)

Determination of $\mathrm{LC}_{50}$ of a sigmoidal concentration response (variable slope) curve was performed using GraphPad Prism version 4.01 for Windows (GraphPad, Sen Diego, CA, USA). The analysis of the family of data sets generated by four solvent:solvent fractions tested was performed by the global curve-fitting model of nonlinear regression analysis with top and bottom shared among the data sets. In addition, the bottom of the curve was constrained as $>0$ and the top was constrained as <1.0. A (global) best-fit value that applies to the family of data sets was computed for each of these shared parameters, while best-fit $\mathrm{LC}_{50}$ value (unshared parameter) was calculated with 95\% confidence interval for each of the data sets (fractions). The relative bioactivity of the fractions was further assessed by comparing the best-fit $\mathrm{LC}_{50}$ value of the various fractions by one-way ANOVA and Tukey's multiple comparison test, which was performed using GraphPad Prism version 4.01 for Windows. 


\section{Results}

\subsection{Yield of extract and fractions}

The acetone extract gave a yield of $11.80 \mathrm{~g}(9.83 \% \mathrm{w} / \mathrm{w})$, whereas the hexane, chloroform, butanol and 35\% water in methanol fractions of the acetone extract gave a yield of $3.49 \mathrm{~g}(39.08 \%), 0.817 \mathrm{~g}(9.15 \%), 0.64 \mathrm{~g}(7.14 \%)$ and $0.65 \mathrm{~g}(7.27 \%)$ respectively. Water fraction was contaminated with fungi while drying, therefore it was excluded from the study.

\subsection{Egg hatch assay}

Both acetone extract and the fractions of Cassia alata demonstrated inhibitory effect on hatching of eggs in a concentration-dependent manner (Fig. 1). The 35\% water in methanol fraction produce the lowest LC50 value $(0.119 \mathrm{mg} / \mathrm{mL})$, therefore it is more active than the other fractions, although not to a significant level ( $p>0.05)$. The shared statistical parameters of the curve fitting analysis and the best-fit $\mathrm{LC}_{50}$ values for the acetone extract and the fractions are shown in Table 1. Albendazole produced $\mathrm{LC}_{50}$ at low concentration $(0.164 \mu \mathrm{g} / \mathrm{mL})$, indicating susceptibility of the strain of $H$. contortus used in the current study.

Table 1: Egg hatched assay $\mathrm{LC}_{50}$ of $C$. alata test extract and fractions using global sigmoidal (4-parameter logistic) model of curve-fitting.

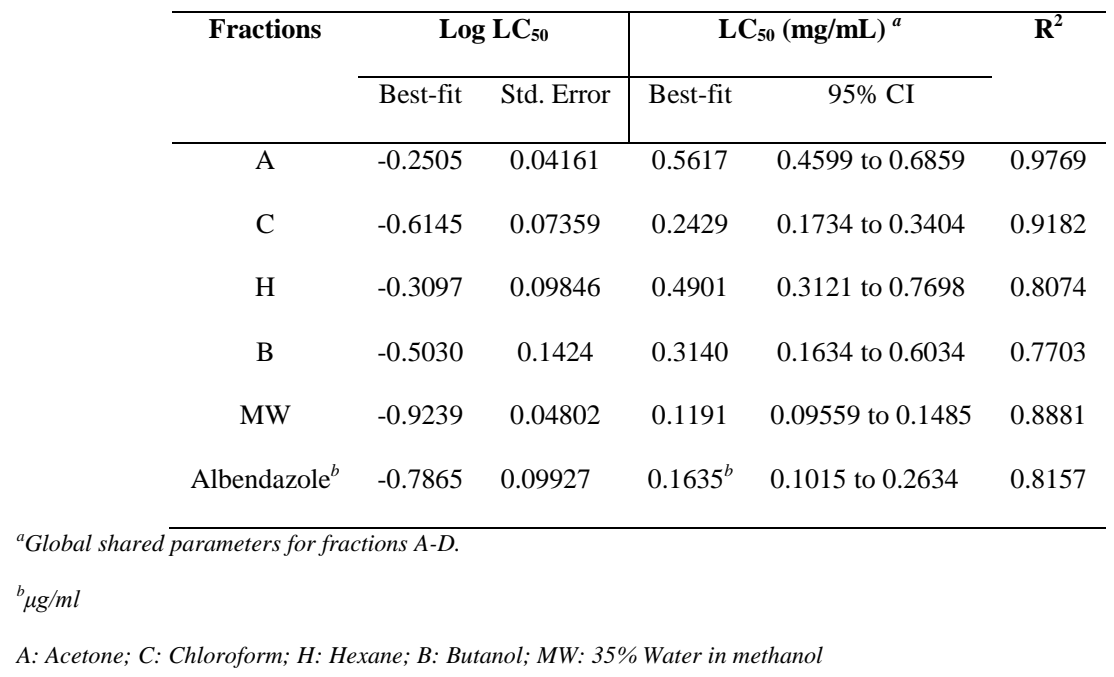



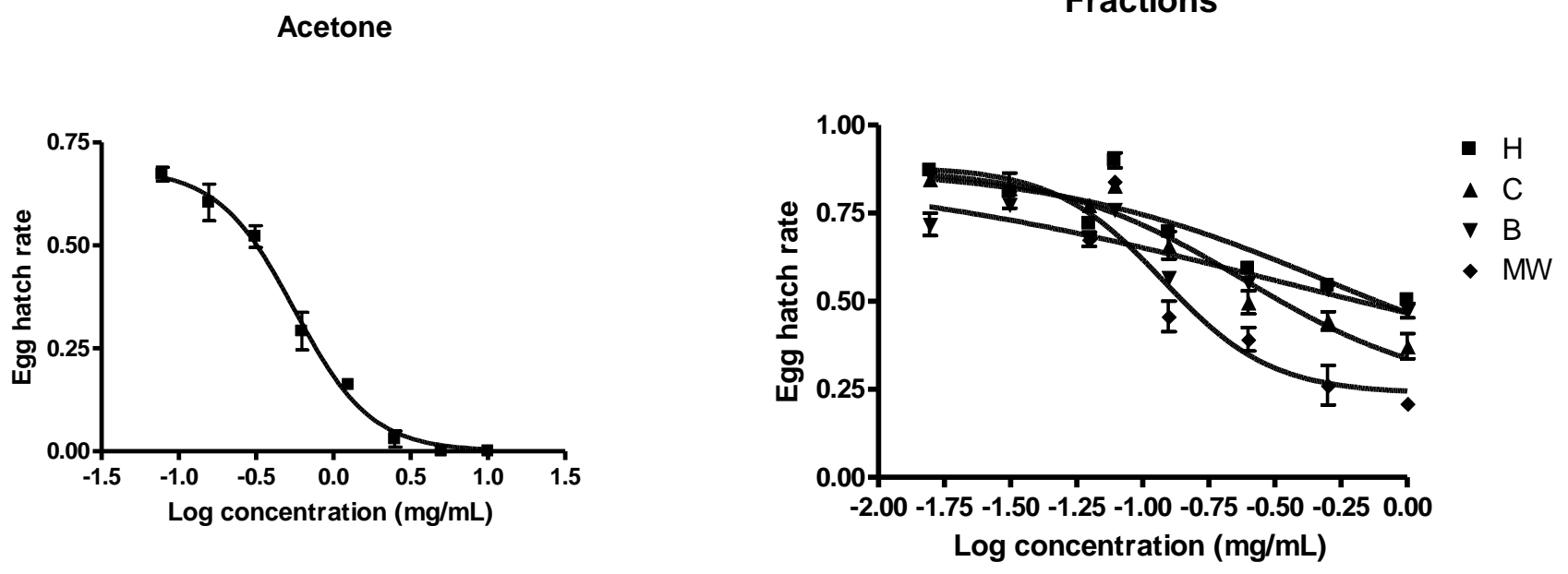

Albendazole

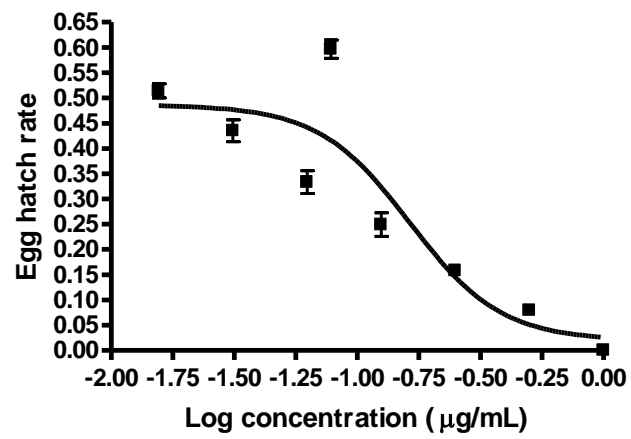

Figure 1: Egg hatch assay concentration-response curve of acetone extract and fractions of $C$. alata, and Albendazole against eggs of $H$. contortus using global sigmoidal model of curve fitting (C: Chloroform; H: Hexane; B: Butanol; MW: 35\% Water in methanol).

\subsection{Larval viability assay}

Acetone extract and the solvent:solvent fractions killed the infective stage $\left(\mathrm{L}_{3}\right)$ of the $H$. contortus larvae (Fig. 2). Table 3 shows Tukey's multiple comparison (post ANOVA) test, which shows that $35 \%$ water in methanol fraction $\left(\mathrm{LC}_{50}=0.040 \mathrm{mg} / \mathrm{mL}\right)$ is significantly more 
active than chloroform and hexane fractions $(\mathrm{p}<0.01)$. However $35 \%$ water in methanol (MW) fraction is not significantly more active than butanol fraction with $\mathrm{LC}_{50} 0.088 \mathrm{mg} / \mathrm{mL}(\mathrm{p}>0.05)$. Albendazole produced $\mathrm{LC}_{50}$ at low concentration $(0.061 \mu \mathrm{g} / \mathrm{mL})$, indicating susceptibility of the strain of $H$. contortus used in the current study.

Table 2: Larval development and viability assay $\mathrm{LC}_{50}$ of $C$. alata test extract and fractions using global sigmoidal (4-parameter logistic) model of curve-fitting.

\begin{tabular}{|c|c|c|c|c|c|}
\hline \multirow[t]{2}{*}{ Fractions } & \multicolumn{2}{|c|}{$\log \mathrm{LC}_{50}$} & \multicolumn{2}{|c|}{$\mathrm{LC}_{50}(\mathrm{mg} / \mathrm{mL})^{a}$} & \multirow[t]{2}{*}{$\mathbf{R}^{2}$} \\
\hline & Best-fit & Std. Error & Best-fit & $95 \% \mathrm{CI}$ & \\
\hline $\mathrm{A}$ & -0.7202 & 0.2529 & 0.1905 & 0.05654 to 0.6416 & 0.9682 \\
\hline $\mathrm{C}$ & -0.2964 & 0.2125 & 0.5054 & 0.1907 to 1.339 & 0.8332 \\
\hline $\mathrm{H}$ & 0.1595 & 0.3342 & 1.444 & 0.3119 to 6.684 & 0.6701 \\
\hline $\mathrm{B}$ & -0.5150 & 0.2349 & 0.3055 & 0.1040 to 0.8972 & 0.8005 \\
\hline MW & -1.393 & 0.2789 & 0.04043 & 0.01126 to 0.1452 & 0.6472 \\
\hline Albendazole $^{b}$ & -0.8422 & 0.08774 & 0.1438 & 0.09436 to 0.2192 & 0.8076 \\
\hline \multicolumn{6}{|c|}{${ }^{a}$ Global shared parameters for fractions $A-D$. } \\
\hline & & & & & \\
\hline
\end{tabular}


Table 3. Tukey's multiple comparison test comparing the $\mathrm{LC}_{50}$ values of fractions of $C$. alata.

\begin{tabular}{llll}
\hline \multicolumn{2}{l|}{ Egg hatch assay } & \multicolumn{2}{l}{ Larval dev. \& viability assay } \\
\hline Comparisons & p value & Comparisons & p value \\
& & & \\
\hline H vs C & $P>0.05$ & $H$ vs C & $P>0.05$ \\
H vs B & $P>0.05$ & H vs $B$ & $P>0.05$ \\
H vs MW & $P>0.05$ & H vs MW & $P<0.01$ \\
C vs B & $P>0.05$ & C vs B & $P>0.05$ \\
C vs MW & $P>0.05$ & C vs MW & $P<0.01$ \\
B vs MW & $P>0.05$ & B vs MW & $P>0.05$ \\
\hline
\end{tabular}

C: Chloroform; H: Hexane; B: Butanol; $M W: 35 \%$ Water in methanol 
Acetone

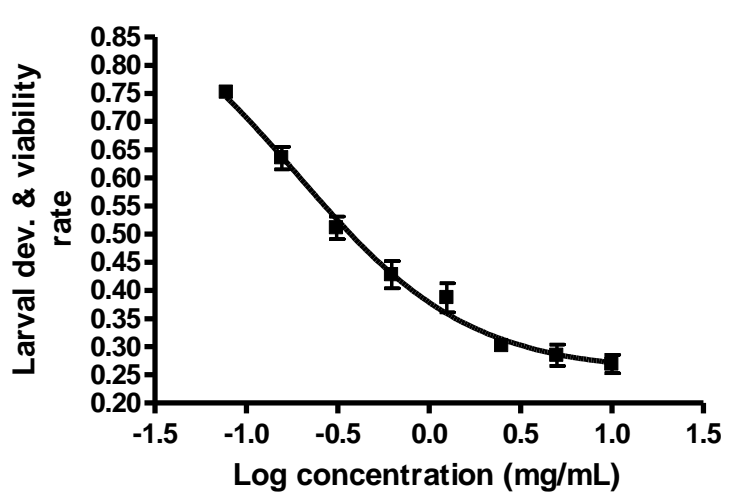

Fractions

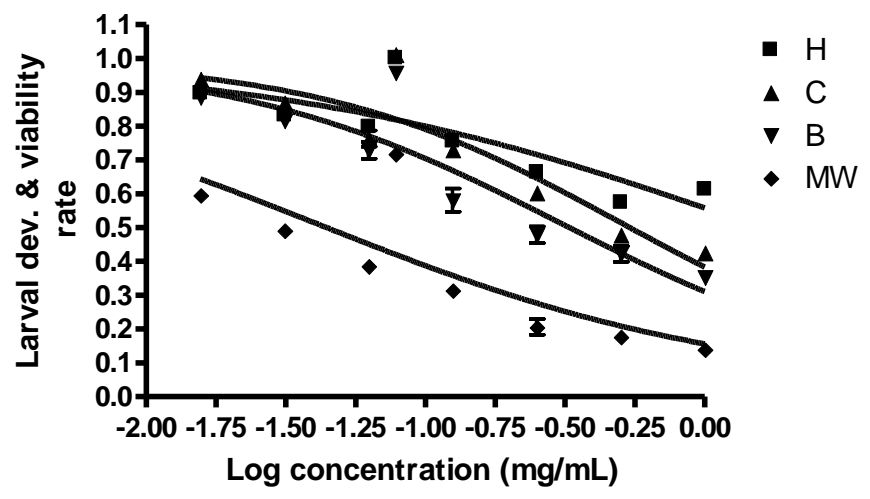

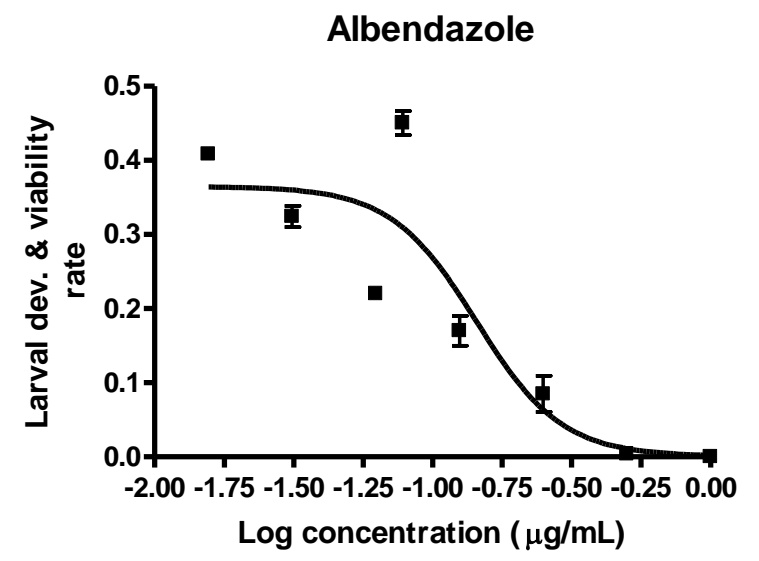

Figure 2: Larval development and viability assay concentration-response curve of acetone extract and fractions of C. alata, and Albendazole against larvae of H. contortus using global sigmoidal model of curve fitting (C: Chloroform; H: Hexane; B: Butanol; MW: 35\% Water in methanol).

\section{Discussion}

The $35 \%$ water in methanol fraction gave the lowest $\mathrm{LC}_{50}$ with egg hatch inhibition and larval viability test. The higher levels of activity observed in the $35 \%$ water in methanol fraction suggest that the anthelmintic component of $C$. alata is a relatively polar compound. The statistical Tukey's multiple comparison (post ANOVA) suggested a significant $(\mathrm{p}<0.01)$ 
difference in the activity of $35 \%$ water in methanol compared with chloroform and hexane fractions when tested on $\mathrm{H}$. contortus larvae. However $35 \%$ water in methanol fraction showed better activity on $H$. contortus ova compared with other fractions, but not to a significant level. Acetone extract of $C$. alata with $\mathrm{LC}_{50}$ of 0.562 and $0.191 \mathrm{mg} / \mathrm{mL}$ against nematode eggs and larvae respectively was shown to be comparable to that obtained for the ethanol extract of Spigelia anthelmia and Nauclea latifolia $\left(\mathrm{LC}_{50} ; 0.625\right.$ and $0.650 \mathrm{mg} / \mathrm{ml}$, respectively) Ademola et al (2007a, 2007b ). An in vitro test for anthelminthic activity on Ascaris suum showed that chloroform alkaloidal extract gave a comparable result to mebendazole at a concentration of $5 \mathrm{mg} / \mathrm{mL}$ Irene (1998). Tadaaki et al (2005) reported anthelmintic effect of $\beta$-carboline alkaloids on Toxocara canis in vivo and in vitro and demonstrated inhibitory effect of isoquinoline alkaloids on movement of second-stage larvae of $T$. canis. The alkaloids in $C$. alata could therefore be responsible for the ovicidal and larvicidal activity observed in this study. Some anthelmintics act by paralysing the worms (such as tapeworm), which then may have to be expelled by a purge; others destroy the parasite through lysis, because they contain proteolytic enzymes such as bromelain [Ananas comosus (L.) Merr.], calotropain [Calotropis procera (Aiton) W.T. Aiton] and pawpaw [Carica papaya L.] Stepek et al (2004). Many constituents with antibacterial activity are also anthelmintic and alkaloids are often the active constituents. Other active anthelmintics are found amongst the flavonoids, terpenoids, mustard-oil heterosides and plants containing proteolytic enzymes Boreham, (1995).

A large number of the biological effects of saponins have been ascribed to their action on membranes. In fact, their specific ability to form pores in membranes has contributed to their common use in physiological research Menin et al (2001), Plock et al (2001). Saponins have long been known to have a lytic action on erythrocyte membranes and this property has been 
used for their detection. Saponins could induce a permeability change on liposomal membrane without cholesterol when they are glycosylated at both C3 and C28 (bidesmosidic) of the oleanolic aglycone $\mathrm{Hu}$ et al (1996). Therefore either of the reported constituents of C. alata could be responsible for the activity or a synergistic effect of the constituents.

Although the use of plant extracts as phytomedicines is becoming increasingly popular as alternative to the use of single molecule synthetic drugs, accurate knowledge of the composition is still warranted.

\section{Conclusions}

The use of the crude methanol extract of the powdered leaf of $C$. alata may therefore be a useful and effective phtyomedicine for controlling nematodes in livestock production. Further in vitro and in vivo investigations of the isolated fractions should be conducted to make use of this plant for therapeutic purposes. The active principles that induced the observed anthelmintic activity might be found in one or both of these classes of chemicals.

\section{Acknowledgement}

University of Ibadan, Nigeria for granting staff development leave and the National Research foundation South Africa funded the work. 


\section{References}

Ademola, I.O., Fagbemi, B.O, Idowu, S.O., 2007a Anthelmintic activity of Spigelia anthelmia extract against gastrointestinal nematodes of sheep. Parasitology Research 101, 63-69

Ademola, I.O., Fagbemi, B.O, Idowu, S.O., 2007b Anthelmintic efficacy of nauclea latifolia extract against gastrointestinal nematodes of sheep:in vitro and in vivo studies. African Journal of Traditional and Complimentary Medicine 4, 148 - 156

Adjanahoun, E., Ahyi M.R.A, Ake-Assi, L., Elewude, J.A., Fadoju, S.O., Gbile, Z.O, Goudole, E., Johnson C.L.A., Keita, A., Morakinyo, O., Ojewole, J.A.O., Olatunji, A.O., Sofowora, E.A., 1991 Traditional medicine and pharmacopoeia. Contribution to ethnobotanical floristic studies in Western Nigeria, Pub. Organization of African Unity, Scientific Technical and Research Commission Lagos, Nigeria. p. 420.

Boreham, P.F.L., 1995 Dreamtime, devastation and deviation: Australia's contribution to the chemotherapy of human parasitic infections. International Journal for Parasitology 25, 1009-1022.

Coles, G.C., Bauer, C., Borgsteede, F.H., Geerts, S., Klei, T.R., Taylor, M.A., Waller, P.J., 1992 World Association for the Advancement of Veterinary Parasitology (W.A.A.V.P.) methods for the detection of anthelmintic resistance in nematodes of veterinary importance. Veterinary Parasitology 44, 35-44.

Eloff, J.N., 1998 Which extractant should be used for the screening and isolation of antimicrobial components from plants? Journal of Ethnopharmacology 60, 1-8

GraphPad Software, 2004 San Diego, CA, USA, http://www. graphpad.com

Gupta, D., 1991. Flavanoid glycosides from Cassia alata. Phytochemistry 30, 2761-2763.

Hu, M., Konoki, K., Tachibana, K., 1996 Cholesterol-independent membrane disruption caused by triterpenoid saponins. Biochimica et Biophysica Acta - Lipid Metabolism 1299, 252-258.

Hubert, J., Kerboeuf, D., 1992 A microlarval development assay for the detection of anthelmintic resistance in sheep nematode Veterinary Record, 130, 442-446. 
Hubert, J., Kerboeuf, D., 1984 A new method for culture of larvae used in diagnosis of ruminant gastrointestinal strongylosis: comparison with faecal cultures. Canadian Journal of Complementary Medicine 48, 63-71.

Irene, M.V., Robert, M.T.G., Rosette, C.G., 1998 Bioactivity studies on the alkaloid extracts from seeds of Leucaena leucocephala. Phytotherapy Research 11, 615 - 617

Leeuwenberg, A.J.M., 1987 Medicinal and poisonous plants of the tropics, Proceedings and symposium 5-35 of the $14{ }^{\text {th }}$ International Botanical Congress, Berlin. p 97.

Menin, L., Panchichkina, M., Keriel, C., Olivares, J., Braun, U., Seppert, E.K., Saks, V.A., 2001 Macrocompartmentation of total creatine in cardiomyocytes revisited. Molecular and Cellular Biochemistry 220, 149-159.

Plock, A., Sokolowska-Kohler, W., Presber, W., 2001 Application of flow cytometry and microscopical methods to characterize the effect of herbal drugs on Leishmania spp. Experimental Parasitology 97, 141-153.

Stepek, G., Jerzy, M.B., Buttle, D.J. Duce, I.R., 2004 Natural plant cysteine proteinases as anthelmintics? Trends in Parasitology 20, 322-327.

Suffness, M., Douros, J., 1979 Drugs of plant origin. Methods in Cancer Research 26, 73-126.

Tadaaki S., Akiko H., Nobuaki, A., Kazuo, K., Koichiro, F., Tamotsu N., 2005 Toxocara canis: Search for a potential drug amongst $\beta$-carboline alkaloids in vitro and mouse studies Experimental Parasitology 110, 134-139 